\title{
Knowledge and Attitude on Febrile Seizure among Mothers with Under-Five Children
}

\author{
Jihan Alifa Syahida, ${ }^{1}$ Nelly Amalia Risan, ${ }^{2}$ Vita Murniati Tarawan ${ }^{3}$ \\ ${ }^{1}$ Faculty of Medicine Universitas Padjadjaran, ${ }^{2}$ Department of Child Health Faculty of Medicine \\ Universitas Padjadjaran/Dr. Hasan Sadikin General Hospital Bandung, ${ }^{3}$ Department of Physiology \\ Faculty of Medicine, Universitas Padjadjaran
}

\begin{abstract}
Background: Febrile seizures frequently occur in children under 5 years old and usually create fear and anxiety among parents. Poor understanding of febrile seizure among parents contributes to mismanagement of seizure. The objective of this study was to identify the knowledge and attitude on febrile seizure among mothers of under five children.

Methods: This descriptive community-based survey comprised of 96 mothers with under 5 children who were chosen through randomization. This survey was, conducted in Hegarmanah Village, Jatinangor, West Java, Indonesia in October 2013. Data were collected using a questionnaire and analyzed using frequency analysis.

Results: Fifty nine respondents $(61 \%)$ considered that high fever in their children will result in seizure and 63 mothers (65\%) stated that this condition was a life-threatening situation which could lead to brain damage (50\%) and paralysis (50\%). There were some respondents who would manage seizure by shaking $(27 \%)$ or holding the child tightly during seizure $(22 \%)$ and putting spoon into the children mouth (59\%). Sixty respondents $(62.5 \%)$ prevented febrile seizure by giving them coffee.

Conclusions: Knowledge and attitude regarding febrile seizure is good, but the knowledge and attitude towards the outcome and what to do during febrile seizures occasion are still poor. [AM].2016;3(4):649-
\end{abstract} 54]

Keywords: Attitude, children under five, febrile seizure, knowledge, mother

\section{Introduction}

Febrile seizure (FS) is a common type of acute seizure occurred in children within one episode of high fever. ${ }^{1}$ It usually happens when the body temperature is above $38.4^{\circ} \mathrm{C}^{1,2}$ Febrile seizure is divided into two types, simple and complex febrile seizures. Simple seizure is usually defined based on the following criteria: 1) takes less than 10-15 minutes and 2) generalized tonic-clonic, tonic, clonic or atonic. Complex seizure is defined based on one or more of the following features: 1) a focal onset or showing focal deficit during seizure attack, 2) a duration longer than 15 minutes and 3) occur more than once during the first 24 hours. $^{3}$

The onset of febrile seizure reaches its peak between the age of 18-22 months years and most cases occurred between 6 month-3 years of age.,3 Most febrile seizures occur in the first 24 hours of an illness. ${ }^{4}$ The most common disease that triggers a febrile seizure is ear infections of any cold or viral infection. ${ }^{5}$

A febrile seizure can be very frightening for parents. ${ }^{2}$ In consequence, parents' ignorance and poor understanding about how to deal with seizure and their anxiety will lead to mismanagement of febrile seizure. Knowledge on febrile seizure is improtant for parents, especially knowledge regarding febrile when it will occur, seizure characteristics, how to manage seizure, and how seizure can be prevented. Febrile seizure does not usually last long; however, correct management can prevent complications such as head injury, mouth and teeth injury, and neck suffocation. Parents also have to understand the right time to bring their children to the nearest health

Correspondence: Jihan Alifa Syahida, Faculty of Medicine, Universitas Padjadjaran, Jalan Raya Bandung-Sumedang Km.21, Jatinangor, Sumedang, Indonesia, Phone: +62 81214660606 Email: jihan_alifa@yahoo.com 
facility when febrile seizure occurs. Hence, the aim of this study was to identify the knowledge and attitude on this disease among mothers with under five children experiencing febrile seizure.

\section{Methods}

This descriptive study was conducted during the period of 8th-19th October 2013 in Desa Hegarmanah, Jatinangor, West Java, Indonesia. This village was one of the villages in Jatinangor used as the site for the research of the medical students of Universitas Padjadjaran. Mothers with under five children were included in this study. A minimum sample size of 96 was calculated using the rapid survey formula. Sampling was performed using stratified random sampling method with 7 mothers were selected as respondents from each area of the 14 village areas of Desa Hegarmanah.

Ninety six mothers were asked to fill out a questionnaire. The questionnaire included items regarding mother's identity (age, education, residency status), history of having children who experienced febrile seizure, as well as their knowledge and attitude about febrile seizure. Respondents who could not read had their questionnaire explained and read out by a facilitator to ensure good understanding of the questions and the same perception as the researcher's. The questionnaire was validated using nonparametric correlation Spearman's rho method. All data were entered and analyzed for frequency using a computer software. This study was approved by the Health Research Ethics Committee of the Faculty of Medicine Universitas Padjadjaran

\section{Results}

A total sample of 96 mothers was selected, but 5 respondents did not complete information on mother's identity, such as missing information on maternal education and febrile

Table 1 Demographic Characteristics of Mothers

\begin{tabular}{lcc}
\hline \multicolumn{1}{c}{ Items } & Frequency (n=96) & Percentage (\%) \\
\hline Mother's age (years old) & 4 & 4 \\
$\leq 20$ & 41 & 43 \\
$21-30$ & 44 & 46 \\
$31-40$ & 7 & 7 \\
$>40$ & & \\
Maternal education & 1 & 1 \\
No entry & 15 & 16 \\
Elementary & 32 & 33 \\
Junior high school & 42 & 44 \\
Senior high school & 4 & 4 \\
Diploma & 2 & 2 \\
College & & \\
Residency status & 86 & 90 \\
Native & 10 & 10 \\
Immigrant & & \\
Febrile seizure history in their children & 4 & 4 \\
No entry & 19 & 76 \\
Yes & 73 & \\
No & & \\
\hline
\end{tabular}




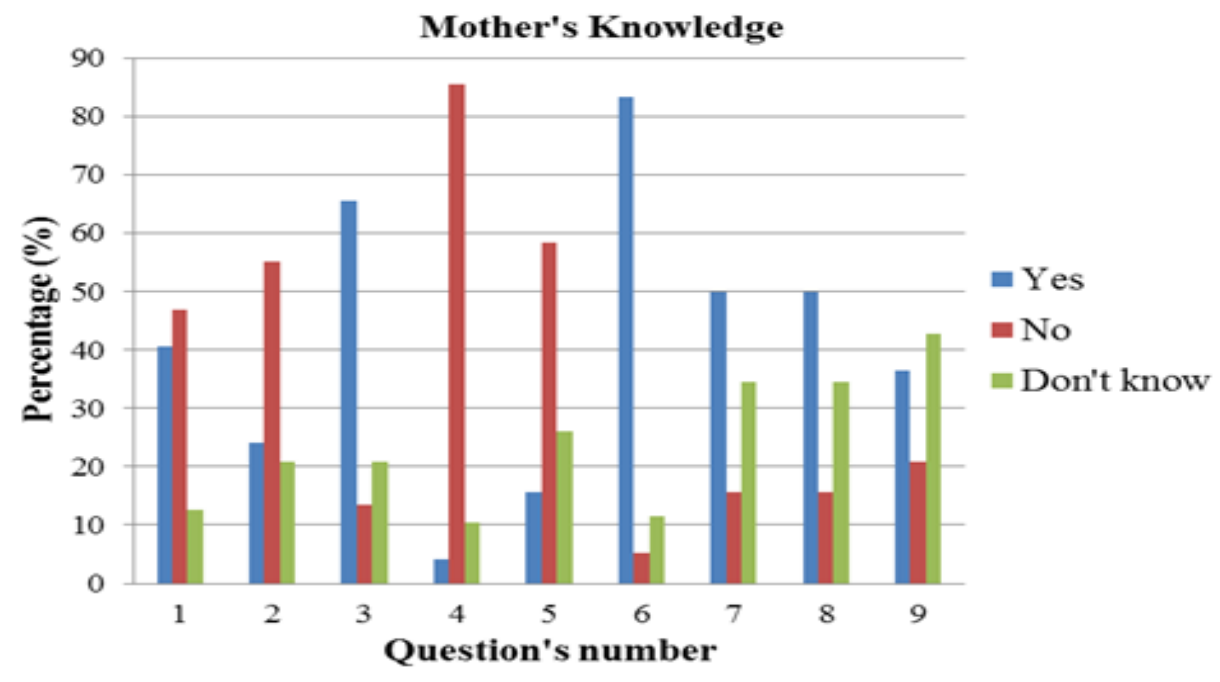

Figure 1 Mother's knowledge chart regarding febrile seizure. 1. High fever will always lead to seizure; 2 . Febrile seizure is epilepsy; 3 . Febrile seizure is a life-threatening disease; 4 . Febrile seizure caused by evil spirit; 5 . Febrile seizure caused by genetic; 6 . Child is unconscious during seizure; 7. Febrile seizure can cause brain damage; 8. Febrile seizure can cause paralysis; 9. Febrile seizure will outgrow

seizure history in their children. However, this does not interfere with the results of mother's knowledge and attitude. Average age of the respondents was between 31-40 years old with most of them graduated from senior high school, lived in Jatinangor sub district and had no history of having children with febrile seizuren (Table 1).

From the knowledge-related items, it was discovered that some respondents thought that high fever would not always lead to seizure $(47 \%)$, febrile seizure equals to epilepsy (55\%), it is a life-threatening disease $(66 \%)$, it is caused by evil spirit (85\%), it is not related to genetic factors $(58 \%)$, children iss unconscious during seizure (83\%) and this condition may cause brain damage $(50 \%)$ or paralysis $(50 \%)$. They had no idea whether febrile seizure would outgrow as the children grow older (43\%) (Figure 1).

Fifty three mothers (55.2\%) agreed that seizure can occur during high fever, and that periodic temperature measurement is needed during fever (56\%) while antipyretic medicine is compulsory (51\%). They agreed to put spoon into children mouth $(59 \%)$ in febrile seizure occasion, but they disagreed to shake the children $(54 \%)$ or to hold the children tightly $(60 \%)$ to cease the seizure. They also disagreed on whether their children will be alright if experiencing febrile seizure
(59\%) while they strongly agreed to take the children to the nearest health care facilities or physicians (65\%). Sixty mothers agreed that giving coffee can prevent the seizure during high fever and that seizure can recur during next febrile occasion (69\%) (Figure 2).

\section{Discussion}

This study revealed that most respondents believed that high fever always leads to seizure. According to other studies, seizure most commonly occurs when children have risk factors such as upper respiratory infection and acute otitis media, parental history of febrile seizure, neonatal hospitalization $>30$ days, and delayed development. ${ }^{5,6}$ on the contrary, one study reported by Parmar et al. ${ }^{7}$ in Mumbai, India stated that $77.9 \%$ parents do not know that seizure can occur during one febrile occasion.

As many as 23 respondents (24\%) believed that febrile seizure meant epilepsy. This result is similar to that of a study done by Kayserili ${ }^{8}$ in 2007 in Turkey, that 35 parents $(28.7 \%)$ have the same opinion. Febrile seizure is different from epilepsy but epilepsy can be a complication of febrile seizure when there are several risk factors. The risk factors are family history of epilepsy, any atypical appearance during seizure or afterwards, 


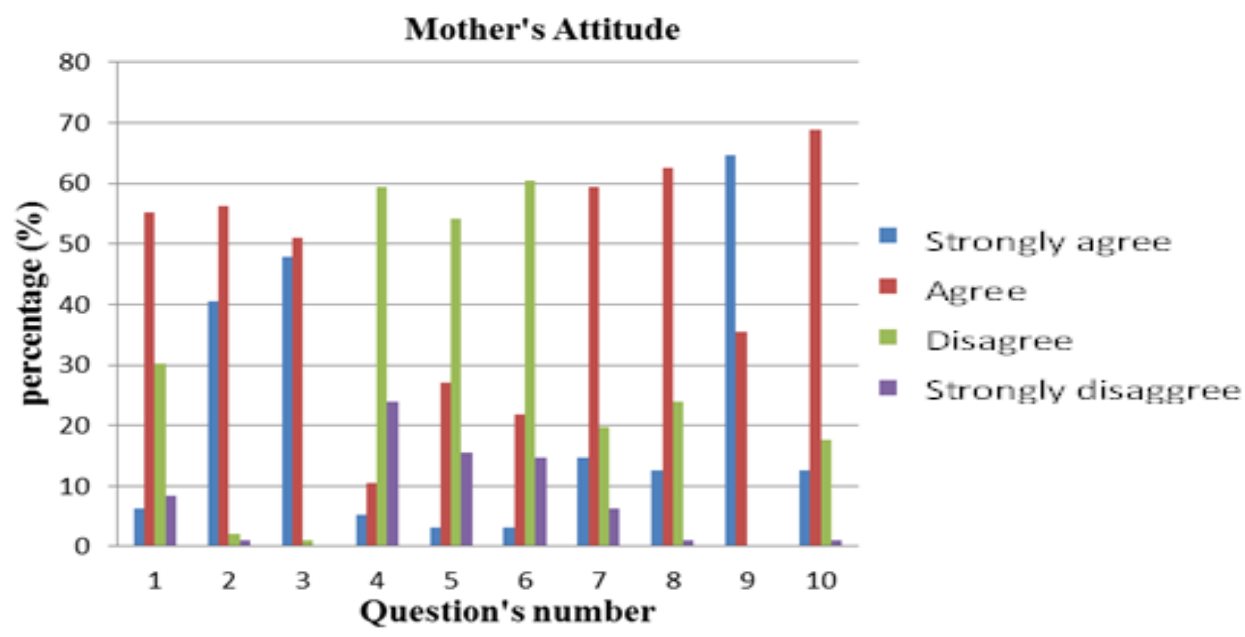

Figure 2 Mother's attitude chart regarding febrile seizure. 1. Seizure can occur during high fever; 2. During fever it is important to do periodic temperature measurement; 3. During fever, it is obligatory to give antipyretic medicine; 4 . If my child experiencing febrile seizure, he/she will be alright; 5 . To cease the seizure, I will wake my child up or shake him/her; 6 . I will hold tightly my child during seizure; 7. I will insert a spoon or other items into child's mouth to prevent tongue biting; 8. Giving coffee powder can prevent or stop the seizure; 9 . At febrile seizure incident I have to take my child to the physician or health care facilities; 10. Febrile seizure can re-occur during next febrile occasion.

first febrile seizure occurs before the age of 9 months, delayed development according to age milestone or any previous neurologic impairment. Epilepsy incidence is $9 \%$ in children experiencing simple febrile seizure with risk factors but only $1 \%$ in children without risk factors. There are $15-70 \%$ risks of seizure recurrence during the first two years after the first seizure. This risk will increase in children less than 18 month of age, have low grade fever and short duration before the seizure onset, and family history of febrile seizure. ${ }^{9}$

Another finding reveals that more than half respondentsstillconsidered thatgeneticfactors do not play a role in febrile seizure. Moreover some respondents thought that febrile seizure is due to evil spirit. Other studies depicted that there is a genetic factor that contributes to febrile seizure, i.e. mutation of sodium and gamma-aminobutyric acid (GABA) channel. ${ }^{2}$ Sodium channel plays an important role in the process of nerve excitation and GABA channel influences inhibitory responses. ${ }^{8}$ Mutation causes hyperexcitation of neurons and results in seizure. Poor environment in pregnancy also contributes to the development of febrile seizure. ${ }^{10}$ A study in Nigeria by Anigilaje ${ }^{11}$ in 2010 shows that the subjects also attribut it to "angry gods" (51.8\%), "evil spirit" (49.0\%) as the cause of childhood seizure.

More than $50 \%$ respondents considered febrile seizure as a life-threatening condition and relate it to unconsciousness, brain damage and paralysis of the child. These findings are similar to study in Turkey $^{8}$ which revealed $107(87.7 \%)$ parents believed the same. However, morbidity and mortality caused by febrile seizure are considered low. There is no mortality and cognitive impairment reported by the US National Collaborative Perinatal Projects (NCPP). Moreover there is no intelligent quotient (IQ) difference in children with history of febrile seizure from their siblings. British cohort study reported similar result in the prognosis of children with febrile seizure compared to other children without the condition. ${ }^{1}$ Other retrospective study revealed that any neurological deficit in few cases occurs only in long-lasted and frequent febrile seizure. ${ }^{12}$

Most respondents have already understood that febrile seizure will outgrow usually after five years old, similar to a study in Turkey ${ }^{8}$ which stated $75.4 \%$ parents knew febrile seizure can be outgrown.

In terms of respondents' attitude toward febrile seizure, more than half respondents 
believed that seizure occurs during high grade fever. Study in Nigeria by Oche and Onankpa ${ }^{13}$ in 2012 showed only 28\% mothers know that fever can lead to seizure. Febrile seizure may occur if there is an elevation of body temperature in children (rectal temperature of $38^{\circ}$ due to extracranium process) ${ }^{12}$ with $38.4^{\circ} \mathrm{C}$ as the lowest temperature to reach to be considered as febrile seizure. ${ }^{1}$

This study also shows that almost all respondents measure their children body temperature periodically during fever and try to decrease the fever by giving antipyretic medicine. They believed that these actions will prevent seizure. A similar result is also found in one study, showing that 119 parents (97.5\%) will measure child body temperature periodically during fever. ${ }^{8}$ Another study in Japan by Sakai et al. ${ }^{14}$ in 2009 shows that mothers whose children have febrile seizure history know that high fever can cause seizure and antipyretic is used to prevent it. Seizure in febrile seizure is always triggered by fever; therefore, antipyretic should be given to control the fever. ${ }^{1}$ Other study revealed that antipyretic could reduce the risk of recurrence seizure. No recommendation is given for giving anti-epilepsy or antipyretic medication continuously to prevent the recurrence of febrile seizure. ${ }^{9}$

More than $75 \%$ respondents did not agree that their children will be alright during febrile seizure and this finding also reflects respondent's anxiety when their children experience febrile seizure. Anxiety increases when febrile seizure occurs in the first time when they do not know what to do and how the prognosis of febrile seizure would be. Studies in India by Parmar et al. ${ }^{7}$ in 2001 and Nigeria by Anigilaje ${ }^{15}$ in 2012 exhibited that mortality is the most feared among mothers whose children experiencing seizure.

Few parents try to cease seizure by waking up, shaking the children, or holding them tightly. Most of them would insert spoon into child mouth to prevent tongue-biting. This practice is unfortunately harmful for children because it may injure the children. In Nigeria ${ }^{15}$ and Turkey ${ }^{8}$, improper management of seizure has also been found such as inserting hand or spoon into children mouth $(74,61.2 \%)$ and $48(39.3 \%)$ parents will find any items to put into the children's mouth during seizure. As many as $43(35.2 \%)$ parents will shake their children during seizure. ${ }^{8}$ Proper management of seizure includes making sure that the child is away from harmful object to prevent injury, lie the children down on one side of their body, loosen their clothes especially in the neck area, put pillow or soft object below children head, do not put anything into mouth, and count the seizure duration in minute. . $^{8,16}$

There are $70 \%$ respondents who believed that giving coffee could prevent the occurrence of febrile seizure. There are no studies to support this theory. This practice was done by respondents during febrile occasion and in normal condition as they received this information from their parents.

All respondents agreed to take their children to the physician while experiencing febrile seizure. This finding is in line with a Nigerian $^{15}$ study in which parents will take their children to hospital at the onset of febrile seizure $(414,82.8 \%)$. However, due to the short duration of febrile seizure, usually the seizure has already ceased at the hospital arrival. Proper management of seizure other than the above is to give diazepam suppository (rectally). ${ }^{1}$

More than $80 \%$ respondents agreed that febrile seizure will recur in the next febrile occasion. This possibility is supported by the fact that seizure is always triggered by fever. This study is a descriptive study so no analysis on the relationship between mother's characteristics and mother's knowledge and attitudeswas performed.Stratified randomized sampling was used by collecting 7 respondents from each area of the village, which does not relate to the proportion of mothers in each area. This was because of the limited time to do the study. Most of the references are from Turkey, Nigeria, and India, because they have approximately the same characteristics as Indonesia as developing countries. Moreover, studies regarding knowledge, attitude, and practice towards febrile seizure is quite a few.

In overall, most mothers have good knowledge and attitude on the cause and prevention of febrile seizures, but some mothers still do not have the knowledge on what to do during febrile seizures occasion and the prognosis of febrile seizures. Further analytical study with bigger sample is needed to do analytical study in Jatinangor to evaluate the association between mother's characteristics and the knowledge and attitude regarding febrile seizure. A multicenter study is also needed to include the diversity of culture, belief, and education to show if there is any different in knowledge and attitude toward febrile seizure. Public education about febrile seizure and what to do during febrile seizures occasion should be included in health care facility program. 


\section{References}

1. Wolf $\mathrm{P}$, Shinnar S. Febrile seizures. In: Maria BL, editor. Current management in child neurology. 3rd ed. Hamilton : BC Decker Inc; 2005. p. 83-7.

2. Shinnar S. Febrile seizures. In: Swaiman KF, Ashwal S, Ferriero DM, Schor NF, editors. Swaiman's pediatric neurology. 5th ed. Philadelphia: Elsevier Saunders; 2012. p. 790-97.

3. Aliabad GM, Khajeh A, Fayyazi A, Safdari L. Clinical, epidemiological and laboratory characteristics of patients with febrile convulsion. J Compr Ped. 2013;3(4):134-7.

4. Daoud A. Febrile seizures: review article. J Med J. 2008;42(3):170-3.

5. Kundu GK, Rabin F, Nandi E, Sheikh N, Akhter S. Etiology and risk factors of febrile seizure - an update. Bangladesh J Child Health. 2010;34(3):103-112.

6. Sankar R, Menkes JH, Koh S, Wu J. Febrile seizures. In: Menkes JH, Sarnat HB, Maria BL, editors. Child neurology. $7^{\text {th }}$ ed. Philadelphia: Lippincott Williams \& Wilkins; 2006. p. 919-22.

7. Parmar RS, Sahu DR, Bavdekar SB. Knowledge, attitude and practices of parents of children with febrile convulsion. J Postgrad Med. 2001;47(1):19-23.

8. Kayserili E, Unalp A, Apa H, Asilsoy S, Hizarcioglu M, Gulez P, et al. Parental knowledge and practices regarding febrile convulsions in Turkish Children. Turk J Med Sci. 2008;38(4):343-50.
9. Graves RC, Oehler K, Tingle LE. Febrile seizures: risks, evaluation, and prognosis. Am Fam Physician. 2012;85(2):149-53.

10. Visser AM, Jaddoe VW, Hofman A, Moll HA, Steegers EA, Tiemeier H, et al. Fetal growth retardation and risk of febrile seizures. Pediatrics. 2010;126(4):919-25.

11. Anigilaje EA, Anigilaje 00. Perception of childhood convulsion among women in a peri-urban community in Ilorin, Nigeria. IOSR-JDMS. 2010;4(5):32-8.

12. Pusponegoro HD, Widodo DP, Ismael S. Konsensus penatalaksanaan kejang demam. 2nd ed. Jakarta: Badan Penerbit IDAI; 2006.

13. Oche OM, Onankpa OB. Using women advocacy groups to enhance knowledge and home management of febrile convulsion amongst mothers in a rural community of Sokoto State, Nigeria. Pan Afr Med J. 2013;14(1):49.

14. Sakai R, Niijima S, Marui E. Parental knowledge and perceptions of fever in children and fever management practices: differences between parents of children with and without a history of febrile seizures. Pediatr Emerg Care. 2009;25(4):231-7.

15. Anigilaje EA, Anigilaje 00. Childhood convulsion: inquiry about the concerns and home management among mothers in Tegbesun, a Periurban Community in Ilorin, Nigeria. ISRN Pediatr. 2012;2012:209609.

16. Jones T, Jacobsen SJ. Childhood febrile seizures: overview and implications. Int J Med Sci. 2007;4(2):110-4. 